\title{
Mitochondrial DNA signatures at different spatial scales: from the effects of the Straits of Gibraltar to population structure in the meridional serotine bat (Eptesicus isabellinus)
}

\author{
J Juste $^{1}$, R Bilgin², J Muñoz ${ }^{1}$ and C Ibáñez ${ }^{1}$ \\ ${ }^{1}$ Estación Biológica de Doñana (CSIC), Sevilla, Spain and ${ }^{2}$ Institute of Environmental Sciences, Bogaziçi University, Istanbul, Turkey
}

\begin{abstract}
The meridional serotine bat Eptesicus isabellinus is found in North Africa and the Iberian Peninsula. We analyzed the genetic structure of $E$. isabellinus at two different geographic scales to reveal the historical and ecological patterns that have shaped its populations. The role of the Straits of Gibraltar as an isolating barrier between African and Iberian populations is evaluated and the degree of genetic structure and female-mediated gene flow was assessed at a local scale between neighboring colonies. Populations of $E$. isabellinus from Iberia and northern Morocco show little genetic divergence and share mtDNA haplotypes, indicating that the Straits of Gibraltar are neither
\end{abstract}

an impediment to dispersal nor a cause of genetic differentiation. Our results also suggest that $E$. isabellinus may have dispersed from western Andalusia into northern Morocco after the last glacial period. At a smaller geographic scale, the colonies studied showed high variation in genetic variability and structure, indicating that no female-mediated gene flow is present. This pattern is consistent with a described pattern of independent endemic viral circulation of the bat rabies virus EBLV-1, which was found when studying rabies dynamics in the same serotine bat colonies.

Heredity (2009) 103, 178-187; doi:10.1038/hdy.2009.47; published online 29 April 2009

Keywords: genetic structure; phylogeography; Eptesicus; bats; Control Region; rabies

\section{Introduction}

Advances in population genetics have revealed that historical processes (for example, colonization or isolation in refuges) underlie current ecological processes (for example, breeding structure or gene flow). The scale at which historical and ecological factors interact is attracting increasing attention from ecologists and geneticists (Linhart, 1999). Recent evidence indicates that the relative importance of these processes in shaping observed patterns of genetic variation depends on the geographic scale at which they are studied.

Historically, populations in temperate zones have responded to Pleistocene climatic oscillations by retreating to suitable refugia during cold periods followed by a northward recolonization as climatic conditions improve (Coope, 1994). These contraction/expansion cycles generally leave a signature, traceable both phylogenetically and in populations' genetic structures. At a European scale the southern peninsulas (Iberia, Italy and the Balkan Peninsula) have acted as the main refugia for western Palearctic biotas (Taberlet et al., 1998; Hewitt, 1999). Other areas in North Africa and along the Black Sea have also been suggested as Palearctic refugia (Leroy

Correspondence: Dr J Juste, Estación Biológica de Doñana (CSIC), 41080 Sevilla, Spain

E-mail: juste@ebd.csic.es

Received 18 December 2008; revised 25 March 2009; accepted 27 March 2009; published online 29 April 2009 and Arpe, 2007). In this context, understanding the importance of the Gibraltar and Messina straits in either connecting or isolating African and European biomes is essential for confirming the relevance of North African refugia for present western Palearctic biotas. The signatures left in the populations' genetic structures can also help answer these historical questions and it is predicted that populations from recolonized territories will generally show a relative lack of genetic variability and structure due to recurrent bottlenecks and loss of ancestral lineages. In contrast, older populations occupying Pleistocene refugia will have experienced less dramatic environmental and population changes (Hewitt, 1996; Pinho et al., 2007).

At an ecological scale, meta-population theory describes current populations as groups of more or less genetically related individuals that are spatially divided from other groups by geographic features such as streams, mountains or marine barriers (Hanski, 1999). Geographic characteristics affect the structuring of genetic variability by limiting or enhancing migration and gene flow among populations. These effects would vary in accordance with the particular life history and ecological characteristics of each given species.

In relation to other small mammals, bats are extraordinary for their long lifespan and very slow reproduction rates. Despite their ability to fly, they show relatively high levels of genetic structuring, probably related to their diversified social organization systems: for example, Myotis bechsteinii, Myotis myotis, Macroderma gigas 
and Mystacina tuberculata (Worthington Wilmer et al., 1999; Kerth et al., 2000; Lloyd, 2003; Ruedi and Castella, 2003). The exceptions are the few migratory species, whose populations are typically poorly subdivided for example, Tadarida brasiliensis and Pteropus sp. (Webb and Tidemann, 1996; Russell et al., 2005). In sedentary bat species, the geographic structure of genetic variation seems to be closer to that of large mammals or birds than to similar-sized small mammals (Ditchfield, 2000). This genetic partitioning is determined by an array of factors including dispersion, historical events and/or extrinsic barriers to gene flow (Burland and Worthington Wilmer, 2001).

The meridional serotine bat Eptesicus isabellinus is a North African species that has been recently discovered in the south of the Iberian Peninsula, where its distribution is allopatric with the very similar E. serotinus that occurs in the northern half of Iberia and throughout most of Europe (Ibáñez et al., 2006).

Both Eptesicus species have a crucial role as reservoirs of the most common European bat rabies strain EBLV-1 (Pötzsch et al., 2002), whose circulation dynamics and pathogenesis are currently being investigated (VázquezMorón et al., 2008). Understanding this virus' population dynamics, critical for designing appropriate epidemiological control measures for rabies, requires an understanding of the regional structure, population dynamics and genetic connectivity present in bat host populations.

In this study, we analyze sequences from the Control Region (CR, a fast-evolving mitochondrial marker) to test the hypothesis that dispersion is enhanced in a bat such as E. isabellinus that flies in open areas, and that poor genetic structuring between populations is due to active gene flow across a wide area. We investigated these hypothetical genetic/spatial associations at two different geographic scales: (1) between Iberian and geographically disjunct African populations to evaluate the role of the Straits of Gibraltar as an isolating barrier; and (2) among maternity colonies at local scales to assess the degree of genetic structure and gene flow caused by female movements. Finally, we discuss the results in light of the rabies circulation pattern recently described (Vázquez-Morón et al., 2008) between these bat colonies.

\section{Materials and methods}

\section{Sampling}

We sampled around 20 individuals from each of $10 \mathrm{E}$. isabellinus maternity colonies (populations) in Spain and two in Morocco (Figure 1). Colonies were grouped into four regions: western Andalusia (WAND), with bats from five populations in Huelva and three in Seville Provinces (between 4.7 and $105 \mathrm{~km}$ apart); eastern Andalusia (EAND), with bats from two colonies in Granada Province (more than $200 \mathrm{~km}$ east of WAND); northern Morocco (NMO), with bats from Oulad Ali Mansour (directly across the Straits from Spain); and southern Morocco (SMO), with bats from Oued Tanit, Assafied, near Agadir (several hundreds kilometers inland and at the southernmost point of this species' range).

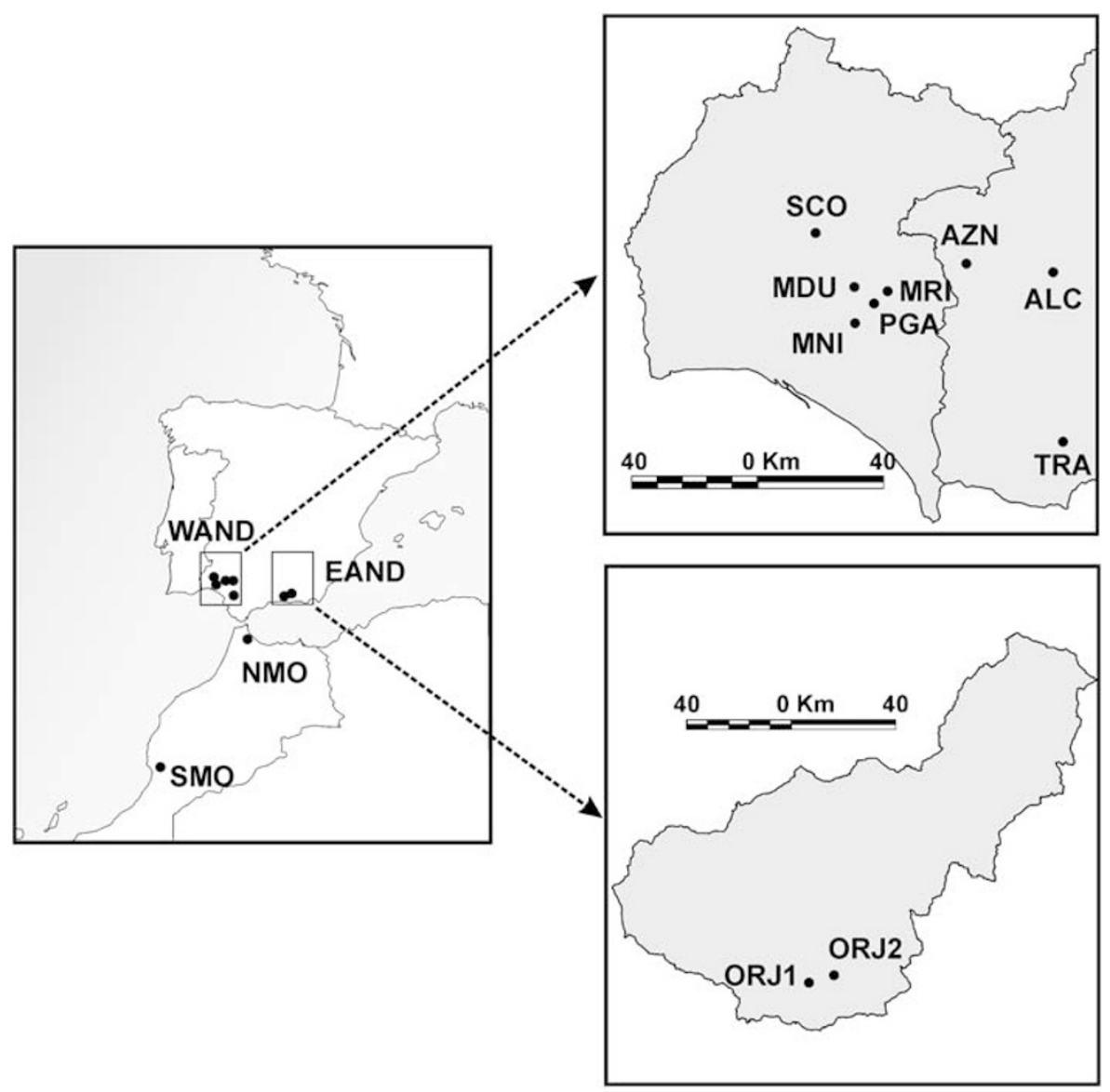

Figure 1 Geographic location of the studied colonies of Eptesicus isabellinus. 
DNA extraction, PCR and sequencing

Total DNA was extracted from wing biopsies following the standard phenol/chloroform protocols (Sambrook et al., 1989) with a few modifications. Isolated DNA was resuspended in $40 \mu \mathrm{l}$ of TE buffer ( $1 \mathrm{M}$ TRIS ( $\mathrm{pH} 8), 0.5 \mathrm{M}$ EDTA ( $\mathrm{pH}$ 8), $\mathrm{H}_{2} \mathrm{O}$ Milli-Q). A fragment of the mitochondrial $\mathrm{CR}$ corresponding to its first hypervariable region (HVI) was amplified using primers $\mathrm{H}-15926\left(5^{\prime}-\right.$ TGAATTGGAGGACAACCAGT-3') and CSBF-R (5'-GTT GCTGGTTTCACGGA GGTAG-3') (Wilkinson and Chapman, 1991). Polymerase chain reaction (PCR) mastermix was prepared to $50 \mu \mathrm{l}$ as the final reaction volume, which included $2 \mu \mathrm{l}$ of DNA extract, $1 \mu \mathrm{l}$ of each primer $(10 \mu \mathrm{M})$, $1 \mu \mathrm{l}$ of $\mathrm{MgCl}_{2}(50 \mathrm{mM}), 0.16 \mu \mathrm{l}$ of $\mathrm{dNTP}(25 \mathrm{mM})$ and $0.5 \mathrm{U}$ of Taq polymerase (Bioline Inc., London, UK). Thermocycling consisted of a $4 \mathrm{~min}$ initial denaturation at $94{ }^{\circ} \mathrm{C}$, followed by 39 cycles of $60 \mathrm{~s}$ at $94^{\circ} \mathrm{C}, 90 \mathrm{~s}$ at $47^{\circ} \mathrm{C}$, and $120 \mathrm{~s}$ at $72^{\circ} \mathrm{C}$ and a final extension of $10 \mathrm{~min}$ at $72^{\circ} \mathrm{C}$. Amplified PCR products were subjected to electrophoresis through a $0.8 \%$ agarose gel to check molecular size. All PCR products were purified and sequenced in both directions using the appropriate primers in an ABI 3100 automated sequencer (Applied Biosystems Corp., Foster City, CA, USA) following the manufacturer's protocols. Sequences were aligned and edited using Sequencher 4.5 (Gene Codes Corp., Ann Arbor, MI, USA).

\section{Phylogeographic inferences}

Phylogenetic relationships between haplotypes were first inspected using maximum parsimony (MP) and Bayesian posterior probability optimality criteria. Previously, the best-fitting substitution model was selected by the Akaike information criterion (AIC) implemented in Modeltest 3.06 (Posada and Crandall, 1998). Under MP, trees were obtained after a heuristic search with an initial tree obtained by step-wise addition (random input order) of the taxa, followed by a complete tree-bisection-reconnection branch swapping. This process was repeated 100 times. Topologies were obtained by differential weighting of transversions based on the maximum likelihood (ML) estimates of the Ts/Tv ratio value. The robustness for each topology was then assessed through bootstrapping (Felsenstein, 1985) using 2000 replicates. MP analyses were performed using the software PAUP* version $4.0 \mathrm{~b} 10$ (Swofford, 2001). The Bayesian inference was obtained using MrBayes version 3.01b (Huelsenbeck and Ronquist, 2001) with random starting trees without constraints. Five simultaneous Markov chains were run for 2000000 generations and trees were sampled every 100 generations. Resulting burn-in values were determined empirically after tree likelihood scores reached stationary values. The values for model parameters were treated as unknown variables to be estimated in each analysis. Two separate analyses were run to ensure that trees converged on the same topology and similar parameters. Net genetic distances within the defined geographic regions were estimated under the selected model using MEGA 3.1 software (Kumar et al., 2004). Relationships between haplotypes were also represented by a statistical parsimony network (Crandall and Templeton, 1999) obtained with the software TCS version 1.21 (Clement et al., 2000).

\section{Population structure and demographic inferences}

Polymorphism was characterized for populations and regions using the following descriptors: haplotype diversity, segregating sites, nucleotide differences and nucleotide diversity, estimated with DnaSP 4.10.9 (Rozas et al., 2003) and Tajima's $D$ statistic (1989) to test for neutrality of mutations within populations. Analysis of molecular variance (AMOVA; Excoffier et al., 1992) on the 12 colonies defined as populations and the four regions was used to explore the distribution of the genetic variability. $\phi_{\text {st }}$, an $\mathrm{F}_{\text {st }}$ analogue for mitochondrial DNA, was used to analyze the degree of structuring between colonies. Restricted gene flow between two populations can be inferred if the genetic distance, measured as $\phi_{\text {st }}$, is significantly greater than zero. The AMOVA computations and $\phi_{\text {st }}$ values between colonies were calculated using the program Arlequin version 2.0 (Schneider et al., 2000). In a related approach, an isolation-by-distance test was used to determine if there was any association between genetic and geographic distances. This was carried out by means of a linear regression of pair-wise geographic distances and genetic distances between colonies. The logarithms of geographic distances between colonies were coupled with genetic distances standardized as $\left(1-\phi_{\text {st }}\right) / \phi_{\text {st }}$ (Rousset, 1997) for this analysis. To improve understanding of migration patterns, we then analyzed the genetic relationships between groups under coalescent theory using the software Migrate 3 (Beerli, 2008). Markov chains Monte Carlo (MCMC) sampling designs were used to obtain ML and Bayesian between-population (BP) estimates of migration rates (in each direction). For the ML approach, the parameters $Q$ (effective population size) and $M$ (migration rate) scaled by the mutation rate per site were estimated simultaneously using estimates from the $F_{\text {st }}$ matrix as starting values. These new estimates for $Q$ and $M$ and the empirical ts $/ \mathrm{tv}$ value $(\kappa=13)$ were used for consecutive final runs. The final MCMC sampling strategy consisted of 10 short chains (sampling 500000 genealogies) and three long chains (sampling 5000000 genealogies) with a burn-in period of 10000 trees, and an adaptive heating regime with four parallel chains and standard initial relative temperatures of 1, 1.2, 1.5 and 6.0. For the Bayesian approach, we used uniform distributions as priors and we obtained posterior probabilities for the parameters based on 5000 samples from a probability landscape defined by 25000000 visited genealogies of which the first 200000 were disregarded (burn-in). The robustness of estimates was assessed by examining convergence in different independent runs of the MCMC.

Finally, we investigated the geographic structure of genetic variation by means of a nested clade phylogeographic analysis (NCPA), which examines geographic association between haplotypes and suggests possible causal processes. This is considered a powerful phylogeographic tool despite recent controversy about its performance (Panchal and Beaumont, 2007; Petit, 2008; but see Templeton, 2008). NCPA examines geographic structuring of haplotypes, with a null hypothesis of a random association between geographic and genetic information (Templeton, 1998). If nonrandom associations are found, NCPA helps indicate whether contemporary (restricted gene flow) or historical forces (past population fragmentation, range expansions or longdistance colonization) best explain the association. We used this approach as corroborating evidence (Garrick et al., 2008) and to reevaluate the association between 
distance and genetic flow, a Mantel test (1000 permutations) was used, as implemented in the program GenAlEx version 6.3 (Peakall and Smouse, 2005). A nested design was built from the statistical parsimony network following Templeton and Sing (1993) and GeoDIS version 2.0 (Posada et al., 2000) was used to test the associations between clades and geographic distances. The most recent inference key was used to interpret results (Templeton, 2004).

\section{Results}

\section{Sequence analysis and variation}

For 254 individuals of E. isabellinus, PCR products resulted in the amplification of the left domain of the CR, a fragment of variable length ranging from 600 to $900 \mathrm{bp}$. As for other mammals, this domain consists of an initial fragment followed by a motif repeated several times that varies between bat species (Wilkinson et al., 1997) and populations of a given species (Wilkinson and Chapman, 1991). E. isabellinus samples typically showed a motif of $82 \mathrm{bp}$ repeated from two to five times. Fifteen individuals from six populations showing uncertain sequence readings were disregarded and the remaining unambiguous 239 sequences were trimmed to a homologous fragment of $240 \mathrm{bp}$ that included only the initial fraction of the HVI region. The repeats were disregarded because they showed an unclear pattern of evolution (Wilkinson and Chapman, 1991; Petit et al., 1999). The selected fragment had 21 polymorphic sites, of which 17 were parsimony informative (GenBank accession numbers EU 183062-183081). Some haplotypes were quite abundant and widespread (for example, Eisa02 and Eisa03), although most were exclusive to just one or two populations. Two haplotypes (Eisa03 and Eisa07) were found on both sides of the Straits of Gibraltar and two colonies were fixed for the same Eisa02 haplotype.

\section{Phylogeographic inferences}

A TrN evolution model (Tamura and Nei, 1993) with an estimated proportion of invariable sites $(I)=0.613$ and a uniform rate between sites was selected by the AIC as the best fit for our data. These parameters were used to set the priors in the posterior probabilities sampling for the Bayesian approach. The Bayesian and the MP phylogenetic reconstructions indicated an almost identical and quite poor geographic arrangement of haplotypes (Figure 2). Both approaches provided good evidence for a well-supported monophyletic group of unique haplotypes from southern Morocco (SMO) and a second group that included all northern Moroccan (NMO) and Iberian haplotypes (WAND and EAND). The genetic distance between NMO and WAND was only slightly larger (0.005) than the distance between the two Iberian regions (0.004). In contrast, the distance between the two African regions was three times larger (0.017). Relationships between haplotypes as revealed by the parsimony-based network were better defined (Figure 3). In this network, southern Moroccan (SMO) haplotypes were still highly differentiated from the rest, although eastern Andalusian (EAND) haplotypes clustered slightly apart from those from both western Andalusia (WAND) and northern Morocco (NMO). These last two regions were closely related and shared two haplotypes.

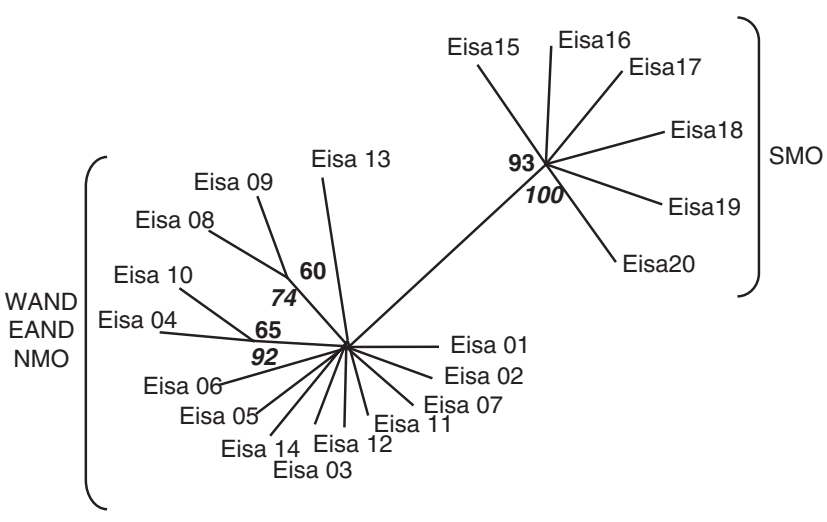

Figure 2 Phylogenetic relationships among haplotypes of $E$. isabellinus based on maximum parsimony (MP) and Bayesian approach (BP) using a Tamura-Nei sequence evolution model. Bootstrap values of maximum likelihood (ML) after 2000 replicates (above branches) and Bayesian posterior probabilities after sampling 20000 trees (below).

\section{Population structure and demographic inferences}

Genetic structure and diversity values (Table 1) varied greatly between populations and even between populations located only a few kilometers apart (for example, $7.9 \mathrm{~km}$ between Puente Gadea and Molino del Duende). Tajima's $D$ statistics were not significant for any colony, suggesting that neither population subdivision, selection nor demographic fluctuations were causing any departure from neutral expectations.

Of the regions, SMO showed the highest values for almost all within-population genetic parameters, even though it had the smallest sample size (Table 1). Genetic haplotype diversity was highest in the southernmost population (SMO) (Table 1), despite the fact that it did not share haplotypes with any other population. The AMOVA results indicated shallow geographic structuring. In fact, most of the variation $(44.93 \%)$ was explained by the 'within-population' factor, whereas 'betweenregion' variation accounted for only $14 \%$ of the total. Nevertheless, overall fixation indices were still significant for regions. Computation of the pair-wise $\phi_{\text {st }}$ values between populations showed that all but one of the comparisons were significantly higher than zero (Table 2), suggesting a hypothesis of restricted female-mediated gene flow between colonies. Migration rates between the four regions, as estimated by $4 \mathrm{Nm}$, also supported the idea of restricted gene flow, with values significantly smaller than one. The Mantel test did not show any association between genetic and geographic distances $(P=0.6)$. All estimates using both ML and BP methods of the migration parameter $M$ indicated a consistently asymmetric between-region pattern of migration. All runs showed relatively low migration values within regions (low values driven to near 0 by the ML analysis). A number of low connection values were seen between the Andalusian regions (EAND and WAND) and between northern (NM) and southern Morocco (SM). Nevertheless, somewhat surprisingly relatively high migration rates were found to occur from Andalusia to northern Morocco, particularly from WAND (Table 3). The theoretical estimates consistently showed a pattern of gene flow from Iberia to North Africa across the Straits of Gibraltar. 


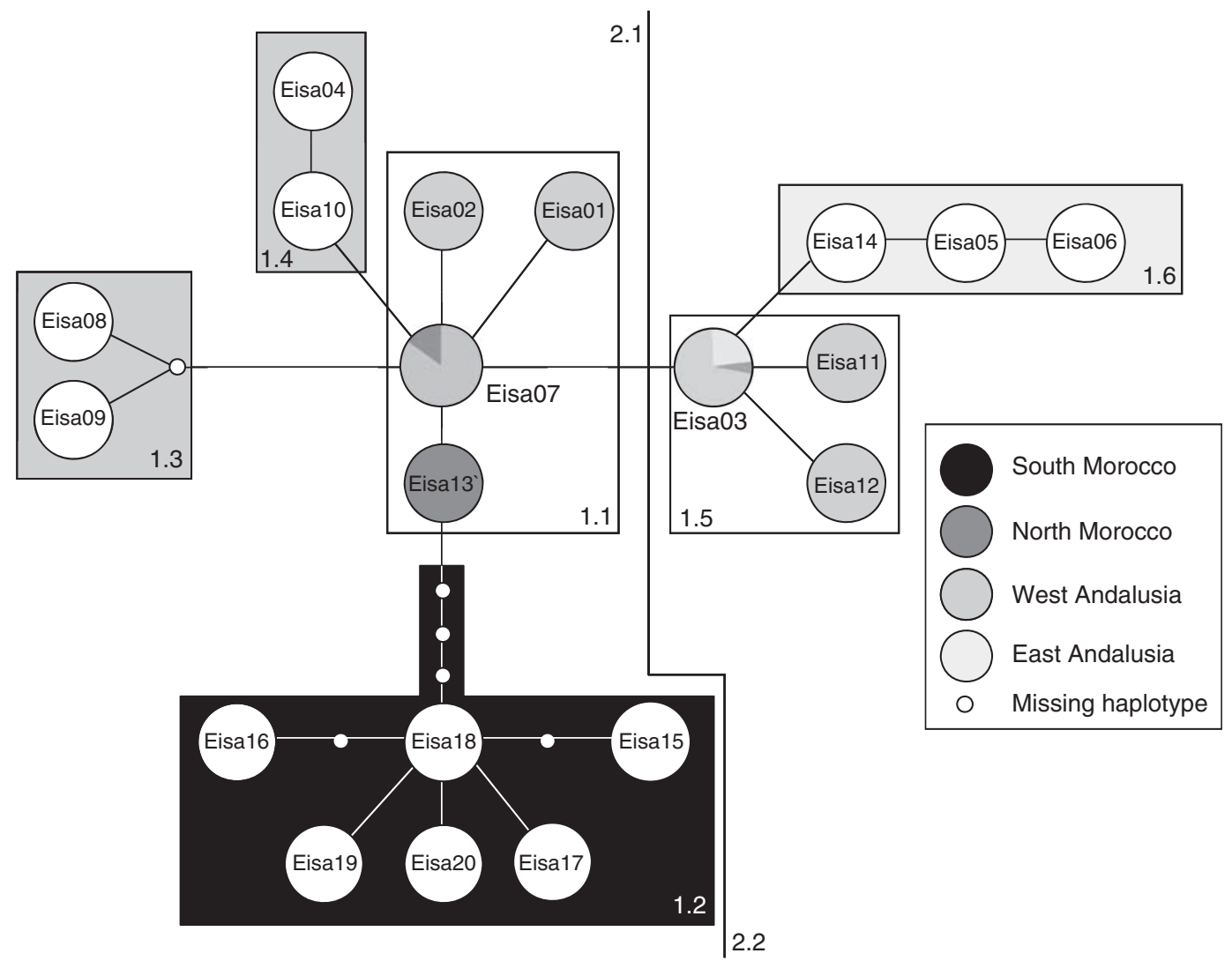

Figure 3 Nested clade design from the statistical parsimony network using 239 sequences of a 240 bp fragment of the hypervariable region (HVI) (Control Region, CR) of E. isabellinus. Circles are not proportional to the sampling size.

Table 1 Descriptive statistics of genetic diversity in a $240 \mathrm{bp}$ long fragment of the mtDNA CR from12 colonies of the meridional serotine bat E. isabellinus

\begin{tabular}{|c|c|c|c|c|c|c|}
\hline Colony & Haplotype & Haplotype diversity & Segregating sites & Nucleotide differences & Nucleotide diversity & Neutrality test \\
\hline & $N$ & $\mathrm{Hd}$ & $\mathrm{S}$ & $K$ & $\mathbf{P i}$ & $D$ \\
\hline ORJ1 (21) & 3 & 0.667 & 3 & 1.286 & 0.00536 & 1.910 \\
\hline ORJ2 (17) & 3 & 0.581 & 2 & 1.044 & 0.00437 & 1.423 \\
\hline EAND (38) & 4 & 0.696 & 3 & 1.6381 & 0.00687 & - \\
\hline TRA (22) & 5 & 0.744 & 5 & 1.541 & 0.00646 & 0.367 \\
\hline ALC (19) & 4 & 0.637 & 5 & 1.789 & 0.00746 & 0.780 \\
\hline AZN (19) & 2 & 0.199 & 2 & 0.398 & 0.00166 & 0.780 \\
\hline MDU (19) & 1 & 0 & 0 & 0 & 0 & - \\
\hline MRI (20) & 2 & 0.479 & 1 & 0.478 & 0.002 & 1.262 \\
\hline MNI (17) & 3 & 0.522 & 3 & 0.676 & 0.00282 & -0.673 \\
\hline PGA (22) & 3 & 0.506 & 4 & 1.259 & 0.00525 & 0.416 \\
\hline SCO (23) & 1 & 0 & 0 & 0 & 0 & - \\
\hline WAND (161 ) & 10 & 0.761 & 10 & 1.83075 & 0.00763 & - \\
\hline NMO (25) & 3 & 0.157 & 2 & 0.233 & 0.00097 & -1.214 \\
\hline SMO (15) & 6 & 0.819 & 7 & 1.638 & 0.00683 & 0.780 \\
\hline Total (239) & 20 & 0.852 & 21 & 2.567 & 0.0107 & - \\
\hline
\end{tabular}

Colony names as in text followed by sample sizes in brackets.

Mean population values and totals are in bold.

The nested cladograms constructed for NCPA showed six first-level and two second-level nested clades (Figure 3). The clade containing the SMO samples (clade 1.2) grouped separately from all other groups, as in the phylogenetic analyses. There were significant associations between haplotypes and their geographic distributions in six clades, which included first-level clades 1.1, 1.5 and 1.6, second-level clades 2.1 and 2.2, and the total cladogram (Figure 4). Inferences obtained from NCPA regarding the mechanism for the origin of nested clades were variable. For clades 1.1, 2.1 and 2.2, there was more than one explanation; for clades 1.5 and 1.6, a pattern of isolation-by-distance was supported. Finally, at the whole cladogram level, the analysis pointed toward a scenario of continuous range expansion (Figure 4). 
Table 2 Pair-wise $\phi_{\mathrm{st}}$ values (lower diagonal) and $N m$ values (upper diagonal) between colonies of E. isabellinus

\begin{tabular}{|l|cccccccccccc}
\hline & ORJ1 & ORJ2 & TRA & ALC & AZN & MDU & MRI & MNI & PGA & SCO & NMO & SMO \\
\hline ORJ1 & - & 1.187 & 0.600 & 0.505 & 0.316 & 0.132 & 0.418 & 0.600 & 0.394 & 0.119 & 0.167 & 0.704 \\
ORJ2 & 0.174 & - & 0.501 & 0.456 & 0.686 & 0.096 & 0.460 & 1.303 & 0.373 & 0.086 & 0.133 & 0.575 \\
TRA & 0.294 & 0.333 & - & 0.578 & 0.236 & 0.173 & 0.399 & 0.446 & 0.456 & 0.156 & 0.200 & 0.886 \\
ALC & 0.331 & 0.354 & 0.302 & - & 0.222 & 0.152 & 0.342 & 0.426 & 0.637 & 0.136 & 0.151 & 0.656 \\
AZN & 0.442 & 0.267 & 0.514 & 0.530 & - & 0.031 & 0.246 & 1.588 & 0.222 & 0.028 & 0.056 & 0.237 \\
MDU & 0.655 & 0.722 & 0.591 & 0.622 & 0.889 & - & 0.081 & 0.090 & 1.080 & --- & 0.024 & 0.150 \\
MRI & 0.374 & 0.352 & 0.385 & 0.422 & 0.504 & 0.755 & - & 0.456 & 0.279 & 0.073 & 0.112 & 0.441 \\
MNI & 0.294 & 0.161 & 0.359 & 0.370 & 0.136 & 0.735 & 0.354 & - & 0.391 & 0.080 & 0.119 & 0.499 \\
PGA & 0.388 & 0.401 & 0.354 & 0.282 & 0.530 & 0.188 & 0.473 & 0.390 & - & 0.946 & 0.121 & 0.464 \\
SCO & 0.678 & 0.745 & 0.616 & 0.647 & 0.899 & $\mathbf{0 . 0 0 0}$ & 0.774 & 0.757 & 0.209 & - & 0.022 & 0.133 \\
NMO & 0.599 & 0.653 & 0.555 & 0.624 & 0.818 & 0.911 & 0.691 & 0.678 & 0.674 & 0.919 & - & 0.192 \\
SMO & 0.262 & 0.303 & 0.220 & 0.276 & 0.513 & 0.625 & 0.362 & 0.334 & 0.350 & 0.653 & 0.565 & - \\
\hline
\end{tabular}

All values are significant $(P<0.05)$ except for the one depicted in bold type. In lighter gray are the Andalusian $($ EAND, WAND) colonies and in darker gray the Moroccan colonies (NM, SM).

\section{Discussion}

Phylogeographic inference and the role of the Straits of Gibraltar in E. isabellinus

Our analyses support the differentiation of the southern Morocco population from the other populations, but only show shallow genetic divergence between the populations in Andalusia and northern Morocco. Potentially, bats can colonize large areas with ease by dispersing from isolated refugia and overcoming geographic barriers. Our results indicate that the Straits of Gibraltar have not impeded movements or occasional dispersion events and therefore cannot be considered to be a factor in the genetic differentiation of E. isabellinus populations. On the other hand, the lack of shared haplotypes between the northern and southern Moroccan populations was a particularly unexpected result and indicates that the Middle and High Atlas mountains, as well as the highlands in between, represent an effective geographic barrier to this species. The Atlas mountains play a similar isolating role in other organisms such as lizards (Brown et al., 2002; Harris et al., 2002) and freshwater turtles (Fritz et al., 2005). Alternatively, the differences between southern and northern Moroccan populations may indicate that these colonies were founded by individuals coming from different refugia. To fully understand the historical relationships of the marginal southern Moroccan population, more sampling of North African populations in countries such as Algeria, Tunisia and Libya is needed.

Although only a few kilometers wide $(14 \mathrm{~km})$, the Straits of Gibraltar seem to have acted as an important
Table 3 Migration rate $(M)$ between regions

\begin{tabular}{|c|c|c|c|c|}
\hline & WAND & EAND & NMO & SMO \\
\hline \multirow{3}{*}{ WAND } & & 248.78 & 0 & 0 \\
\hline & 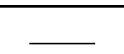 & 109.5 & 91.5 & 55.5 \\
\hline & 0 & - & 0 & 0 \\
\hline \multirow[t]{2}{*}{ EAND } & 715.5 & - & 424.5 & 589.5 \\
\hline & 1844.3 & 0 & $\longrightarrow$ & 0 \\
\hline \multirow[t]{2}{*}{ NMO } & 1531.5 & 979.5 & L & 703.5 \\
\hline & 0 & 0 & 39.6 & $\longrightarrow$ \\
\hline SMO & 79.5 & 26.35 & 109.5 & 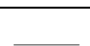 \\
\hline
\end{tabular}

Values are scaled by mutation rate per site.

The table is to be read the following way: for a given population (rows) migration estimates are shown from the regions indicated in each column. Upper values are migration estimates from maximum likelihood and lower values are estimates from Bayesian posterior probabilities.

barrier preventing faunal contacts ever since their reopening at the start of the Pliocene about 5.3 million years ago (Dobson and Wright, 2000). Nevertheless, a 

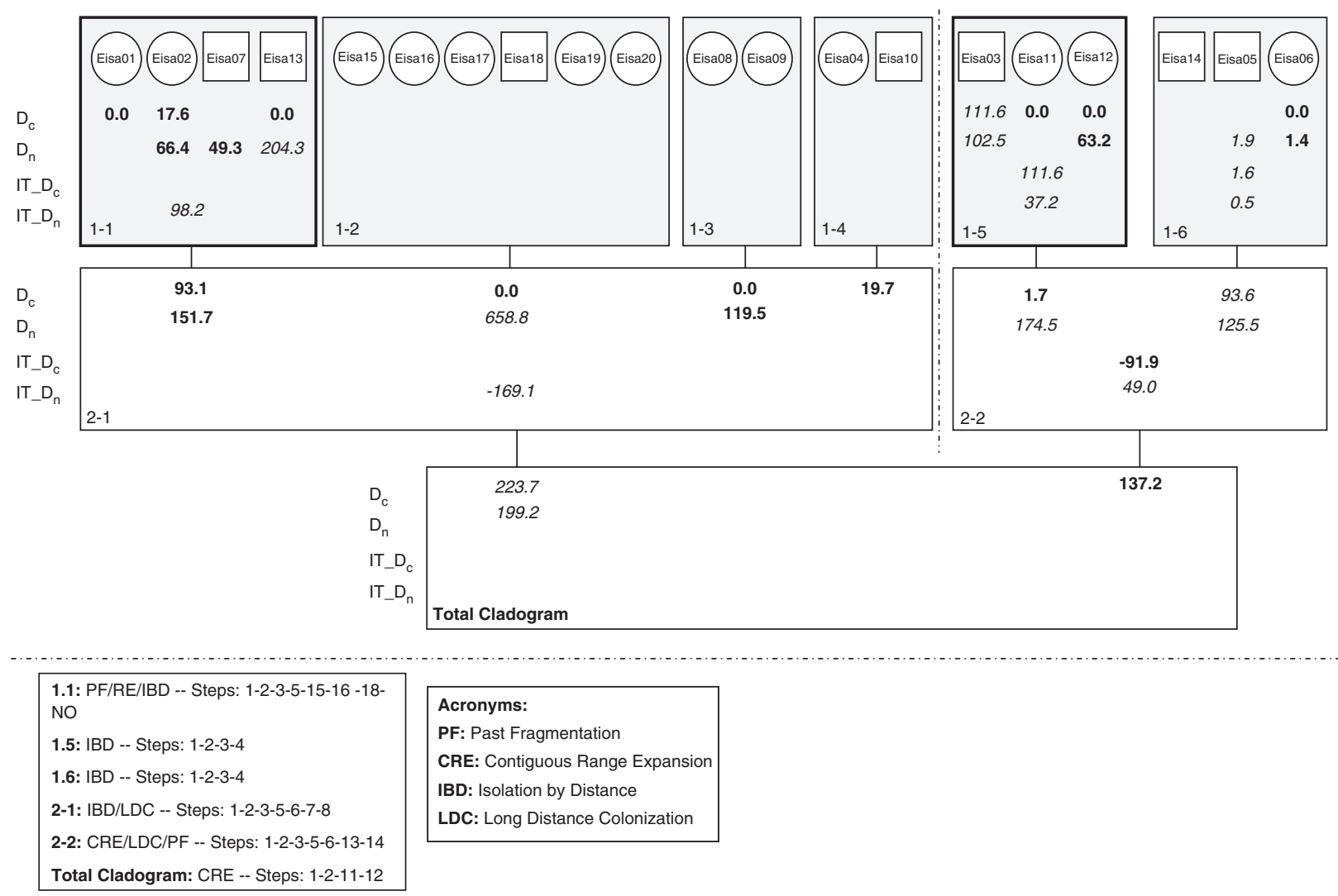

Figure 4 Nested clade phylogeographic analysis (NCPA) statistics and inferences: italicized values are statistically larger, and the values in bold are statistically smaller than expected by chance.

lack of differentiation between one side of the Straits of Gibraltar and the other has been found in birds (Guillaumet et al., 2006), shrews (Brändli et al., 2005), salamanders (Veith et al., 2004) and probably even in worm lizards (Vaconcelos et al., 2006). However, for the bats Myotis myotis (Castella et al., 2000), Myotis nattereri (García-Mudarra et al., 2009), Plecotus austriacus (Juste et al., 2004) and Pipistrellus pipistrellus (Hulva et al., 2004), the Straits of Gibraltar seem to be an effective barrier and to have helped in promoting or maintaining lineages that are genetically highly differentiated.

The lack of evidence for any effect caused by the Straits of Gibraltar or for isolation-by-distance in E. isabellinus could be related to its preference for flying in open areas, although a similar lack of structuring for the Straits of Gibraltar has also been found in Barbastella barbastellus (Juste et al., 2003), a bat with theoretically less powerful flight. The degree of permeability of the Straits of Gibraltar to bats may be the result of a complex equation in which life history traits are also important. A recent comparative approach including all bat species present on both Iberian and African sides of the Mediterranean has shown the absence of a clear pattern regarding the role of the Straits of Gibraltar on bat communities (García-Mudarra et al., 2009), and caution should be taken when drawing general conclusions (Dobson and Wright, 2000).

Coalescence time between the exclusively North African haplotype (Eisa13) and the closest Iberian haplotype (Eisa07) can be inferred using the age in mutations $(\rho=0.74)$ and the mutation rate estimated for this same mtDNA fragment for a related bat species (6.3$25 \%$ per million years; Petit et al., 1999). The estimated divergence time for haplotypes on both sides of the Straits of Gibraltar is between 46 and 12 thousand years ago. According to the network, the distribution of the potentially most ancestral haplotypes (Eisa03 and Eisa07) was restricted almost exclusively to Spanish populations, which suggests that the refugium for this species was located in southern Iberia and that it was from here that it subsequently expanded into North Africa during favorable conditions along any of the Pleistocene climatic pulses. The theoretical migration estimates also suggest a pattern of dispersion from western Andalusia into North Africa. A similar north-south dispersion pattern has been suggested for lizards (Carranza et al., 2006) and freshwater turtles (Fritz et al., 2006). Southwest Iberia seems to have been an important refugium for a variety of species, from cork oaks (López de Heredia et al., 2007), to fish (Carmona et al., 2000) and aquatic invertebrates (Gómez et al., 2000; Muñoz et al., 2008). Despite the need for additional data, our results support the idea that the Iberian Peninsula and, in particular, southwestern Iberia acted as a refugium and genetic source region for both European (Taberlet et al., 1998; Hewitt, 1999), and NorthAfrican biotas.

Genetic structure and gene flow among populations On a smaller geographic scale, the populations studied show remarkable variation in their genetic diversity. The relatively young population at Trajano (TRA, WAND) 
occupying the expansion joints of a road bridge built 30 years ago has one of the highest nucleotide diversities and the highest haplotype diversity of all Spanish populations. The creation of new shelter sites in a highly productive area such as the Guadalquivir marshes may have attracted females from nearby populations and have led to this high diversity. The remaining colonies show striking differences in their degree of genetic structure and variability and all $\phi_{\text {st }}$ pair-wise comparisons other than the monomorphic populations (MDU and SCO) were significant. These results indicate that at local geographic scale high levels of differentiation exist, thus suggesting that no female-mediated contacts between colonies exist. E. isabellinus maternity colonies typically only last from spring to late summer and by autumn bats have moved to other shelter sites, probably only few kilometers apart. It is expected that the colonies on the African side of the Straits will show similarly high levels of structure. However, difficulties in conducting fieldwork have thus far prevented us from assessing this question.

Molecular results agree with the strong philopatric pattern found in the field, in which females return every year to their birth colonies. No case of colony switching has ever been detected in the 10 years we have been banding in these colonies (1709 bats banded and 400 recaptured, Ibáñez et al., unpublished data). Little is known about the process governing the establishment of new colonies, although they are probably founded by a small number of females. With no alleles being added to the population through the recruitment of females from other colonies, random genetic drift would cause the differences we found between colonies and even the fixation of some haplotypes within a few generations. A similar pattern of highly structured colonies has been found in the forest-dwelling bat, Myotis bechsteinii (Kerth et al., 2000, 2002), although its colonies do not have large differences in genetic diversity, indicating that different mechanisms are at work here in colony formation. In this type of social structure usually only males disperse and they are therefore solely responsible for the gene flow between established colonies. mtDNA only gives partial information and further studies based on nuclear markers such as microsatellites are needed to detect the real gene flow between populations.

\section{Geographic scale and genetic signature}

Although it would seem that E. isabellinus is capable of dispersing throughout the entire study area, a process that would lead to a rapid coalescence of colonies, the amount of genetic differentiation observed within regions is markedly greater than between regions. These results, which seem counterintuitive and to contradict the species' ability to cross the Straits of Gibraltar, can only be explained by females' high philopatry. Contacts between different geographic regions take place through occasional dispersion events, most probably by males that homogenize the genetic diversity between populations and maintain the cohesion of species' genetic pool at a regional level. Geographic features-very often the same ones-tailor both historical and ecological processes, making it necessary to work at different scales to understand fully and be able to interpret the patterns occurring in the present. Our results show the impor- tance of the spatial scale in distinguishing historical and ecological processes acting on observed genetic diversity.

\section{Eptesicus genetic structure and rabies epidemiology}

The colonies of $E$. isabellinus that were genetically studied between 1998 and 2003 for this paper were also banded and checked for rabies. Reverse transcriptase-PCR and serology testing found EBLV-1 rabies circulation to be present in nine of the colonies, all in the Iberian Peninsula. Each colony had a different temporal pattern of viral dynamics, suggesting that independent endemic viral circulation occurs in each colony (Vázquez-Morón et al., 2008). Our findings of restricted gene flow between colonies of E. isabellinus based on the genetic analysis of its mtDNA agree with viral epidemiological results and also help explain them. With maternity colonies behaving as closed communities, a pattern of epidemiological circulation by fast-spreading viral waves-as is typical in other viruses-is unlikely to occur. In fact, given that E. isabellinus bats can survive after infection (Pérez-Jordá et al., 1995; Echevarría et al., 2001), vertical transmission within bat colonies (mother-offspring) would be the most likely way for the virus to spread, with only occasional transmission between colonies caused by individual interactions between females and males (for example, mating) at the end of the reproductive season and when maternity colonies disaggregate. Although EBLV-1 has not yet been found in Africa (only around 50 E. isabellinus tested to date), we predict that Eptesicus from Northern Morocco will also carry the rabies virus and that its strains will be very similar to the EBLV-1 rabies strains found in Andalusia.

\section{Acknowledgements}

We thank the following for their help collecting samples: J García-Mudarra, JA Garrido, E Migens, J Nogueras, L Mohamed Aixa, C Ruíz and the Association Sportive de Speleologie de Agadir (Morocco). JL García-Mudarra provided help in the laboratory and Jesus Nogueras helped with the map in Figure 1. A Gomez improved the first drafts of the MS. C Vilá, J Leonard, R Zardoya and S Thompson and two anonymous reviewers improved the paper with helpful comments. We also acknowledge the help provided by P Beerli with his Migrate software. This research was part of the projects SAF2006-12784-C02-02/ and SAF2006-12784-C02-01/ funded by the Dirección General de Investigación of the Spanish Ministry of Science and Technology.

\section{References}

Beerli P (2008). Migrate version 3.0: a maximum likelihood and Bayesian estimator of gene flow using the coalescent. Distributed over the Internet at http://popgen.scs.edu/migrate. html.

Brändli L, Lori-Jayne Lawson L-J, Vogel P, Perrin N (2005). Evolutionary history of the greater white-toothed shrew (Crocidura russula) inferred from analysis of mtDNA, Y, and X chromosome markers. Mol Phyl Evol 37: 832-844.

Brown RP, Suárez NM, Pestano J (2002). The Atlas mountains as a biogeographical divide in North-West Africa: evidence from mtDNA evolution in the Agamid lizard Agama impalearis. Mol Phyl Evol 24: 324-332. 
Burland TM, Worthington Wilmer J (2001). Seeing in the dark: molecular approaches to the study of bat populations. Biol Rev 76: 389-409.

Carmona JA, Domínguez J, Doadrio I (2000). Congruence between allozyme and cytochrome $b$ gene sequence data in assessing genetic differentiation within the Iberian endemic Chondrostoma lemingii (Pisces: Cyprinidae). Heredity 84: 721-732.

Carranza S, Harris DJ, Arnold EN, Batista V, González de la Vega JP (2006). Phylogeography of the lacertid lizard, Psammodromus algirus, in Iberia and across the Strait of Gibraltar. J Biogeogr 33: 1279-1288.

Castella V, Ruedi M, Excoffier L, Ibáñez C, Arlettaz R, Hausser J (2000). Is the Gibraltar Strait a barrier to gene flow for the bat Myotis myotis (Chiroptera: Vespertilionidae)? Mol Ecol 9: 1761-1772.

Clement M, Posada D, Crandall KA (2000). TCS: a computer program to estimate gene genealogies. Mol Ecol 9: 1657-1659.

Coope GR (1994). The response of insect faunas to glacialinterglacial climatic fluctuations. Phil Trans Roy Soc London B 344: 19-26.

Crandall KA, Templeton AR (1999). Statistical methods for detecting recombination. In: Crandall KA (ed). The Evolution of HIV. The Johns Hopkins University Press: Baltimore, MD. pp 153-176.

Ditchfield AD (2000). The comparative phylogeography of neotropical mammals: pattern of intraspecific mitochondrial DNA variation among bats contrasted to nonvolant small mammals. Mol Ecol 9: 1307-1318.

Dobson M, Wright A (2000). Faunal relationships and zoogeographical affinities of mammals in North-West Africa. J Biogeogr 27: 417-424.

Echevarría JE, Avellón A, Juste J, Vera M, Ibáñez C (2001). Screening of active lissavirus infection in wild bat populations by viral RNA detection on oropharingeal swabs. J Clin Microbiol 39: 3678-3683.

Excoffier L, Smouse PE, Quattro JM (1992). Analysis of molecular variance inferred from metric distances among DNA haplotypes-application to human mitochondrialDNA restriction data. Genetics 131: 479-491.

Felsenstein J (1985). Confidence limits on phylogenies: an approach using the bootstrap. Evolution 39: 783-791.

Fritz U, Barata M, Busack SD, Fritzsch G, Castilho R (2006) Impact of mountain chains, sea straits and peripheral populations on genetic and taxonomic structure of a freshwater turtle, Mauremys leprosa (Reptilia, Testudines, Geoemydidae). Zool Scr 35: 97-108.

Fritz U, Fritzsch G, Lehr E, Ducotterd JM, Müller A (2005). The Atlas mountains, not the Strait of Gibraltar, as a biogeographic barrier for Mauremys leprosa (Reptilia: Testudines). Salamandra 41: 97-106.

García-Mudarra JL, Ibáñez C, Juste J (2009). The Straits of Gibraltar: barrier or bridge to Ibero-Moroccan bat diversity? Biol J Linn Soc (in press).

Garrick RC, Dyer RJ, Beheregaray LB, Sunnucks P (2008). Babies and bathwater: a comment on the premature obituary for nested clade phylogeographical analysis. Mol Ecol 17: 1401-1403.

Guillaumet A, Pons J-M, Godelle B, Crochet P-A (2006). History of the crested lark in the Mediterranean region as revealed by mtDNA sequences and morphology. Mol Phyl Evol 39: 645-656.

Gómez A, Carvalho GR, Lunt DH (2000). Phylogeography and regional endemism of a passively dispersing zooplankter: mitochondrial DNA variation in rotifer resting egg banks. Proc Roy Soc London B 267: 2189-2197.

Hanski I (1999). Metapopulation Ecology. Oxford Series in Ecology and Evolution. Oxford University Press: New York.

Harris DJ, Carranza S, Arnold EN, Pinho C, Ferrand N (2002). Complex biogeographical distribution of genetic variation within Podarcis wall lizards across the Strait of Gibraltar. I Biogeogr 29: 1257-1262.

Hewitt GM (1996). Some genetic consequences of ice ages, and their role in divergence and speciation. Biol J Linn Soc 58: 247-276.

Hewitt GM (1999). Post-glacial re-colonization of European biota. Biol J Linn Soc 68: 87-112.

Huelsenbeck JP, Ronquist F (2001). MrBayes: Bayesian inference of phylogenetic trees. Bioinformatics 17: 754-755.

Hulva P, Horáèek I, Strelkov P, Benda P (2004). Molecular architecture of Pipistrellus pipistrellus/Pipistrellus pygmaeus complex (Chiroptera: Vespertilionidae): further cryptic species and Mediterranean origin of the divergence. Mol Phyl Evol 32: 1023-1035.

Ibáñez C, García-Mudarra JL, Ruedi M, Stadelmann B, Juste J (2006). The Iberian contribution to cryptic diversity in European bats. Acta Chiropter 8: 277-297.

Juste J, Ibáñez C, Muñoz J, Trujillo D, Benda P, Karatas A et al. (2004). Mitochondrial phylogeography of the long-eared bats (Plecotus) in the Mediterranean Palaearctic and Atlantic Islands. Mol Phyl Evol 31: 1114-1126.

Juste J, Ibáñez C, Trujillo D, Muñoz J, Ruedi M (2003). Phylogeography of barbastelle bats (Barbastella barbastellus) in the Western Mediterranean and the Canary Islands. Acta Chiropter 5: 165-175.

Kerth G, Mayer F, König B (2000). Mitochondrial DNA (MtDNA) reveals that female Bechstein's bats live in closed societies. Mol Ecol 9: 793-800.

Kerth G, Mayer F, Petit E (2002). Extreme sex-biased dispersal in the communally breeding, nonmigratory Bechstein's bat (Myotis bechsteinii). Mol Ecol 11: 1491-1498.

Kumar S, Tamura K, Nei M (2004). MEGA3: integrated software for molecular evolutionary genetics analysis and sequence alignment. Brief Bioinf 5: 150-163.

Leroy S, Arpe K (2007). Glacial refugia for summer-green trees in Europe and south-west Asia as proposed by ECHAM3 time-slice atmospheric model simulations. J Biogeogr 34: 2115-2128.

Linhart Y (1999). Mosaic landscapes, family structure and evolution. TREE 14: 376-378.

Lloyd BD (2003). Intraspecific phylogeny of the New Zealand short-tailed bat Mystacina tuberculata inferred from multiple mitochondrial gene sequences. Syst Biol 52: $460-476$.

López de Heredia U, Carrión S, Jiménez P, Collada C, Gil L (2007). Molecular and palaeoecological evidence for multiple glacial refugia for evergreen oaks on the Iberian Peninsula. J Biogeogr 34: 1505-1517.

Muñoz J, Gómez A, Green AJ, Figuerola J, Amat F, Rico C (2008). Phylogeography and local endemism of the native Mediterranean brine shrimp Artemia salina (Branchiopoda: Anostraca). Mol Ecol 17: 3160-3177.

Panchal M, Beaumont MA (2007). The automation and evaluation of nested clade phylogeographic analysis. Evolution 61: 1466-1480.

Peakall R, Smouse PE (2005). GenAlEx 6: Genetic Analysis in Excel. Population Genetic Software for Teaching and Research. The Australian National University: Canberra, Australia.

Pérez-Jordá JL, Ibáñez C, Muñoz-Cervera M, Téllez A (1995). Lyssavirus in Eptesicus serotinus (Chiroptera: Vespertilionidae). J Wild Dis 31: 372-377.

Petit R (2008). The coup de grâce for the nested clade phylogeographic analysis? Mol Ecol 17: 516-518.

Petit E, Excoffier L, Mayer F (1999). No evidence of bottleneck in the postglacial recolonization of Europe by the noctule bat (Nyctalus noctula). Evolution 53: 1247-1258.

Pinho C, Harris CJ, Ferrand N (2007). Contrasting patterns of population subdivision and historical demography in three western Mediterranean lizard species inferred from mitochondrial DNA variation. Mol Ecol 16: 1191-1205. 
Posada D, Crandall KA (1998). MODELTEST: testing the model of DNA substitution. Bioinformatics 14: 817-818.

Posada D, Crandall KA, Templeton AR (2000). GeoDis: a program for the cladistic nested analysis of the geographical distribution of genetic haplotypes. Mol Ecol 9: 487-488.

Pötzsch CJ, Müller TH, Kramer M (2002). Summarizing the rabies situation in Europe 1990-2002 from the Rabies Bulletin Europe. Rabies Bull Eur 26: 11-17.

Rozas J, Sanchez-DelBarrio JC, Messeguer X, Rozas R (2003). DnaSP, DNA polymorphism analyses by the coalescent and other methods. Bioinformatics 19: 2496-2497.

Rousset F (1997). Genetic differentiation and estimation of gene flow from F-statistics under isolation by distance. Genetics 145: 1219-1228.

Ruedi M, Castella V (2003). Genetic consequences of the ice ages on nurseries of the bat Myotis myotis: a mitochondrial and nuclear survey. Mol Ecol 12: 1527-1540.

Russell AL, Medellín RA, McCracken GF (2005). Genetic variation and migration in the Mexican free-tailed bat (Tadarida brasiliensis mexicana). Mol Ecol 14: 2207-2222.

Sambrook J, Fritsh EF, Maniatis T (1989). Molecular Cloning: A Laboratory Manual, 2nd edn. Cold Spring Harbor Laboratory Press: Cold Spring Harbor, USA.

Schneider S, Roessli D, Excoffier L (2000). Arlequin: A Software Package for Population Genetics. Genetics and Biometry Laboratory, Department of Anthropology University of Geneva: Geneva, Switzerland.

Swofford DL (2001). PAUP* Phylogenetic Analysis Using Parsimony (and Other Methods) Version 406b. Sinauer Associates: Massachusetts.

Taberlet P, Fumagalli L, Wust-Saucy AG, Cosson JF (1998). Comparative phylogeography and postglacial colonization routes in Europe. Mol Ecol 7: 453-464.

Tajima F (1989). Statistical method for testing the neutral mutation hypothesis by DNA polymorphism. Genetics 123: 585-595.

Tamura K, Nei M (1993). Estimation of the number of nucleotide substitutions in the control region of mitochondrial DNA in humans and chimpanzees. Mol Biol Evol 10: 512-526.
Templeton AR (1998). Nested clade analyses of phylogeographic data: testing hypotheses about gene flow and population history. Mol Ecol 7: 381-397.

Templeton AR (2004). Statistical phylogeography: methods of evaluating and minimizing inference errors. Mol Ecol 13: 789-809.

Templeton AR (2008). Nested clade analysis: an extensively validated method for strong phylogeographic inference. Mol Ecol 17: 1877-1880.

Templeton AR, Sing CF (1993). A cladistic analysis of phenotypic associations with haplotypes inferred from restriction endonuclease mapping IV Nested analyses with cladogram uncertainty and recombination. Genetics 134 659-669.

Vaconcelos R, Carretero MA, Harris DJ (2006). Phylogeography of the genus Blanus (worm lizards in Iberia and Morocco based on mitochondrial and nuclear markers-preliminary analysis. Amphibia-Reptilia 27: 339-346.

Vázquez-Morón S, Juste J, Ibáñez C, Ruíz-Villamor E, Avellón A, Vera $\mathrm{M}$ et al. (2008). Endemic circulation of European bat lyssavirus type 1 in serotine bats, Spain. Emerg Infect Dis 14: 1263-1266.

Veith M, Mayer C, Samraoui B, Donaire D, Bogaerts S (2004). From Europe to Africa and vice versa: evidence for multiple intercontinental dispersal in ribbed salamanders (genus Pleurodeles). J Biogeogr 31: 159-171.

Webb NJ, Tidemann CR (1996). Mobility of Australian flyingfoxes, Pteropus spp. (Megachiroptera): evidence from genetic variation. Proc Roy Soc London B 263: 497-502.

Wilkinson GS, Chapman AM (1991). Length and sequence variation in evening bat D-loop mtDNA. Genetics 128 607-617.

Wilkinson GS, Mayer F, Kerth G, Petri B (1997). Evolution of repeated sequence arrays in the $\mathrm{D}$-Loop region of bat mitochondrial DNA. Genetics 146: 1035-1048.

Worthington Wilmer J, Hall L, Barratt E, Moritz C (1999). Genetic structure and male-mediated gene flow in the ghost bat (Macroderma gigas). Evolution 53: 1582-1591. 